\title{
Interdisciplinary Ecotourism Research: Insights and Issues for Conserva- tion Biology
}

\author{
Susan A. Moore*, David Newsome, Kate Rodger and Amanda J. Smith \\ School of Environmental Science, Murdoch University, South Street, Murdoch WA 6150 Australia
}

\begin{abstract}
A continuing interest in interdisciplinary research characterizes conservation biology. This interest is a response in large part to the increasingly complex problems facing society. Analysis of recent ecotourism research, as an interdisciplinary enterprise, offers insights. As such, this paper analyses two projects - the social and ecological impacts of visitors to the south-western Australian forests, and of interactions between visitors and sea lions off the west coast of Australia. Analysis centers on issues of central concern for interdisciplinary research in conservation biology: poorly defined terms, lack of common goals, unclear or missing conceptual framework, insufficiently explained methods, and a lack of new knowledge achieved through integration. From the reviewed studies, interdisciplinary research appeared possible because the researchers used strategies from more than one discipline while adopting the paradigmatic position of ecology. Unresolved issues were how to work with potentially conflicting epistemologies and methodologies, and rewarding interdisciplinary research.
\end{abstract}

\section{INTRODUCTION}

Today conservation biologists and associated researchers are faced with many challenges, including the complexity of environmental issues [1], almost universal cries for sustainability [2], and the realization that both the natural and social sciences are needed to understand environmental phenomena [3-6]. These challenges are regularly faced by conservation biologists, as they work to understand the world's biodiversity as well as effect social and political changes to conserve it. Research embracing a number of disciplines has been advocated as a critical part of society's response to these challenges [7].

The need for such research to address environmental problems was first identified by ecologists in the 1970s [5], around the same time that there was general societal recognition of the complexity of these problems. In conservation biology, this recognition of the need for multi-disciplinary research has been expressed in several ways. A recent editorial in Conservation Biology [4] notes that the biological sciences are necessary but not sufficient to address environmental problems and the "vital importance of the social sciences to conservation' (p.649). Another indication of this recognition is significant steps towards collaborative research by the Society for Conservation Biology through the creation of the Social Science Working Group in 2003.

Integrative research, a term used in a recently-published comprehensive review of research embracing a number of disciplines in landscape ecology, has been widely advocated as part of the solution to the wider problems of today's complex society, as well as to specifically address the issues facing environmental management [5, 9-13]. A recent report by the National Institute of Medicine suggested that 'Some parts

*Address correspondence to this author at the School of Environmental Science, Murdoch University, South Street, Murdoch WA 6150 Australia; Tel: +618 9360 6484; E-mail: S.Moore@ murdoch.edu.au of the scientific frontier require...the mobilization of interdisciplinary research teams...increasingly, investigators will need to integrate knowledge...And greater prominence must be given to research in the behavioral and social sciences' ([8], 316). Bridging the traditional divides among the social, natural, behavioral and engineering sciences has also been noted as one of the great intellectual challenges of this century [10].

Integrative research has been characterized and thwarted by a lack of clarity regarding definitions $[5,7]$. The collection of research approaches that include more than one discipline has been variously referred to as cross-disciplinary [10], integrative [5, 14, 15], and multiple disciplinary [7]. All these terms generally refer to research incorporating more than one discipline. It is within these 'umbrella' terms that confusion becomes apparent, with terms such as multi-, inter-, and trans- disciplinary used inter-changeably and often ambiguously defined [7]. To provide a consistent although potentially contestable basis for the remainder of this article, the following definitions are provided. These draw in large part from an extensive literature review of health research and services [7], tempered by efforts to clarify these concepts for landscape ecology [5] (Table 1).

Multi-, inter- and trans- disciplinary research separate out on intensity of cooperation and integration between disciplines and the involvement of broader society [5]. Multidisciplinary research, at one end of the spectrum, involves disciplines working side by side but without integration [7]. Researchers exchange knowledge but do not cross the boundaries between disciplines to create new approaches or new integrated knowledge [5]. Interdisciplinary research, the focus of this article, is a synthesis of two or more disciplines achieved by crossing disciplinary boundaries [5, 7]. The result is new integrative knowledge useful to science and society. There are two extra provisos [5]. This form of research must involve several unrelated academic disciplines, that is, ones with contrasting research paradigms. As such, a central 
Table 1. Forms of Integrative Research and Associated Definitions

\begin{tabular}{|c|c|}
\hline Disciplinary Form & Definition \\
\hline $\begin{array}{l}\text { Interdisciplinary } \\
\text { e.g., conservation biology, ecotour- } \\
\text { ism }\end{array}$ & $\begin{array}{l}\text { - Crosses disciplinary boundaries, preferably those of unrelated disciplines. } \\
\text { - Attempt to integrate the epistemology of multiple disciplines around a common problem. } \\
\text { - Development of integrated knowledge and theory. } \\
\text { - New theory can not be broken down into separate disciplinary parts. }\end{array}$ \\
\hline $\begin{array}{l}\text { Transdisciplinary } \\
\text { e.g., ecological economics, land- } \\
\text { scape ecology (some not all) }\end{array}$ & $\begin{array}{l}\text { - Combines interdisciplinarity with a participatory approach. } \\
\text { - Crosses disciplinary and science/society boundaries. } \\
\text { - Development of integrated knowledge and theory among science and society. } \\
\text { - Research approach relying on both scientific and non-academic knowledge (e.g., traditional ecological } \\
\text { knowledge). }\end{array}$ \\
\hline
\end{tabular}

Sources: $[5,7,12,13,18]$

challenge for this form of research is bringing together different epistemologies (i.e., ways of understanding and studying the world). The second proviso is pursuit of a common goal by the researchers.

Transdisciplinary research, at the other end of the spectrum, combines an interdisciplinary approach with participation by society. Such participation is designed to deal with the gap between science and society. Participation can include collaborative development of the research goals and methods, execution of the research and implementation of the research findings. In this form of research the problem being researched transgresses science as a whole [13]. The essential element for such research to be considered transdisciplinary is collectively creating new knowledge [5]. Also important is having a shared conceptual framework [7]. Confusion has been widely caused through the term transdisciplinary being used synonymously with a participatory approach [5].

Similarly to conservation biology, ecotourism is a relatively young field with first formal definition of the word attributed to Hector Ceballos-Lascurain in 1987 [16]. Ecotourism is defined as being nature based, ecologically sustainable, environmentally educative, locally beneficial, and resulting in visitor satisfaction [16]. Also similarly to conservation biology [17, 18], ecotourism research draws on a number of disciplines from the social and natural sciences. Research has included visitor satisfaction, visitor perceptions, ecological impacts and especially impacts on wildlife, and broader issues of sustainability $[16,19]$. Ecotourism also has strong affinities and overlaps with conservation biology given its focus on the natural environment and managing impacts on it by visitors. Conservation biology similarly has a concern with understanding and protecting this environment through understanding social systems $[17,20]$. Given these similarities between conservation biology and ecotourism, both youthful potentially integrative research pursuits, there is strong merit in drawing lessons from one to support and enhance research practice in both.

Several key issues with regards to integrative research todate that need to be considered have been identified [5]. These authors used an online survey of landscape researchers involved in integrative projects, plus a review of papers published by landscape ecologists, to identify these issues among other things. The survey showed a lack of understanding of the different forms of integrative research: in only $47 \%$ of the integrative projects had project members reached a common agreement on what these research concepts mean. This lack of common understanding was identified as a barrier to integration across disciplines. Another key issue, identified through the review of papers, was lack of sufficient detail on methods: this included a lack of details on what integrative methods were developed and used, how integration was operationalized in the study, and what conceptual framework was accessed or developed. Also, if research is crossing discipline boundaries and finding something new, this new contribution should be evident when such research is reported [5]. This is often not the case.

In a recent paper [15], a number of barriers to integrative research in landscape ecology, which are also relevant to conservation biology and the intent of this paper, obtained through a review of literature, reports and research programs, plus qualitative interviews, are explored. Barriers included the previously noted lack of common understanding of the different forms of integrative research, plus researchers being spatially separated making it difficult to regularly meet face-to-face. Numerous researchers have identified the importance of such meetings to develop a common vocabulary, acquire new knowledge, and for each to alter their thoughts, beliefs and behavior. A lack of project design, project management and leadership were also noted as barriers, as was the perceived lack of rewards for such work [21]. This latter point hinged on the perception that there is a slower rate of publication from interdisciplinary studies and it can more difficult to publish in respected journals $[13,15]$.

This paper describes two interdisciplinary research projects centering on ecotourism. One addresses the social and ecological impacts of visitors to the forests of south-western Australia. The other explores the interactions between visitors and sea lions off the west coast of Australia. The associated aims of this paper, based on these projects, are twofold. The first is to provide insights into how the requirements of 'good' interdisciplinary research can be met, where such 
research addresses the aforementioned issues of poorly defined terms, lack of common goals, unclear or missing conceptual framework, insufficiently explained methods, and a lack of new knowledge achieved through integration. The second, related aim is to explore the unresolved issues for interdisciplinary research as practiced by conservation biologists, those researching ecotourism, and many others with similar concerns regarding the conservation of the world's biota and associated natural resources.

\section{SOCIAL AND ECOLOGICAL IMPACTS OF VISITORS IN THE FORESTS OF SOUTH-WESTERN AUSTRALIA}

The south-west corner of Australia is one of the world's 34 biodiversity hot spots [22]. Included are diverse shrublands as well as approximately $34,047 \mathrm{~km}^{2}$ of mixed eucalyptus forest restricted to the area's wetter south-west extremity [23]. These forests include three eucalyptus species found nowhere else: Jarrah (Eucalyptus marginata), Karri (E. diversicolor) and Marri (Corymbia calophylla). They also have a high appeal for tourists, including visitors from overseas and within Australia. Recent figures suggest that 2.38 million tourists visit these forests each year, contributing AUD\$59 million to AUD\$61.9 million to the local economy [24]. Activities include camping, appreciating nature and scenery, and hiking [25]. Towns within this forested area provided accommodation and other facilities but many visitors choose to camp in reserves and national parks within the forest. The following description is derived from research by one of the authors [25] on the impacts of camping. The research had been identified as a priority need by managers who had no system in place to determine or monitor visitor impacts in these forests.

It was guided by a conceptual framework, used implicitly [26] and then explicitly [25] (Fig. 1). In overview, the methods established empirical measurement of social and ecological conditions to determine the impacts caused by visitors (top left hand corner and middle of Fig. 1). Visitor questionnaires were then used to determine the levels of change in these conditions that were acceptable to visitors, generally referred to as standards [16]. The resulting data were combined to determine what conditions had become 'unacceptable' based on an assessment of the field measurements, using the standards obtained from the questionnaires (Fig. 1).

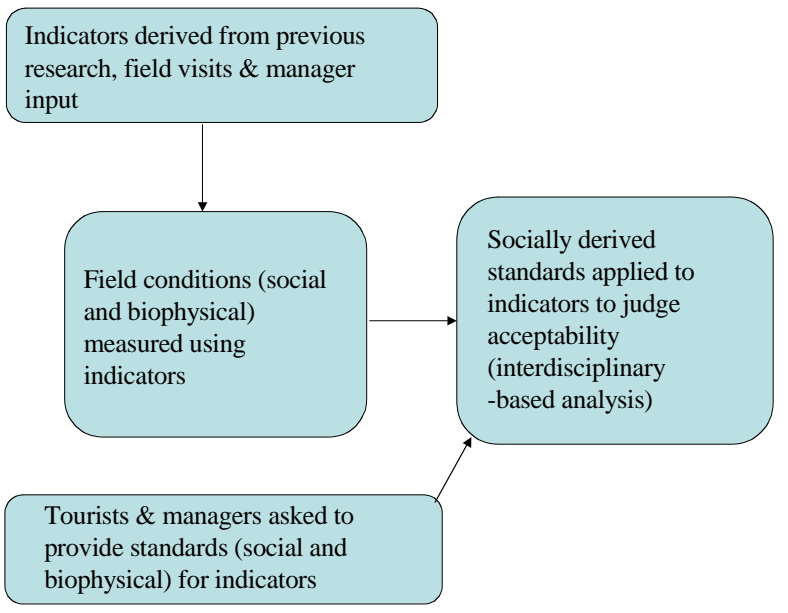

Fig. (1). Conceptual framework for visitor impact-forest research.
Condition measurements were taken at a total of 87 campsites from 5 parks. All sites were located within eucalyptus forest, and all had similar infrastructure and management practices. Infrastructure at these 87 'developed' sites included a cleared, level pad (usually surfaced with gravel) for a tent or tents, parking for 1-2 vehicles, site furniture such as a fire ring and table and benches, and a communal toilet. A suite of indicators was used to measure and report on ecological and social impacts, using a combined survey approach based on multiple indicator measures and ratings [25]. Ecological indicators included human damage to trees and root exposure, with social indicators including litter and 'unplanned' trails (i.e. trails additional to those provided by managers, created over time by visitors, usually as a short cut to other campsites and facilities or to access a water body or other scenic feature) (Table 2). Other indicators measured but not of direct relevance to this paper are not included.

Indicator selection was based on ecological, visitor and managerial significance. Ecological significance was particularly important [27]. Previous visitor surveys in the United States [28] and south western Australia [29] supported these indicators as reflecting conditions of importance to visitors. Local managers were also asked to provide input to this selection process.

The social component of the research, which obtained the standards, was questionnaire-based [25]. A total of 311 visitors $(69 \%$ response rate) and 15 managers (80\% response rate) completed questionnaires. Visitors were asked to identify conditions of importance to them (to cross-check the utility of the indicators measured in the ecological component) and to provide standards (i.e. the maximum acceptable level of change they were willing to accept) for selected indicators [28]. Standards were requested for human damage to trees, root exposure, litter, and unplanned trails (Table 2).

Together the standards provided social information to help judge the acceptability or otherwise of the conditions recorded using the ecologically-focused site-based surveys. A number of other questions were asked of visitors; they are not included here because of their lack of relevance to the aims of this paper. Table 2 summarizes the combined findings regarding current conditions, determined from the ecological component and the judgments about acceptability obtained from analysis of visitor responses. The new knowledge provided by this integrative research is rapid access to information on the conditions where the impacts are unacceptable, namely for tree damage and litter (refer to the last column of Table 2). This integration is illustrated by the last box in Fig. (1).

This research provided managers with information on which sites needed immediate management attention, according to levels of impact regarded as important by visitors and measured using ecological and social indicators (Table 2). Thus, this research developed new integrated knowledge and is illustrative of the immediate benefits of interdisciplinary research.

\section{INTERACTIONS BETWEEN HUMANS AND SEA LIONS}

The second study involves the interactions between visitors and sea lions. Interactions between humans and Australian sea lions (Neophoca cinerea) have increased markedly 
Table 2. Current Forest Conditions and Standards for Acceptable Levels of Impact, as Set by Visitors

\begin{tabular}{|l|l|l|l|}
\hline Indicator & Observed Impact in the Field* & $\begin{array}{l}\text { Standard Derived from } \\
\text { Visitor Questionnaires** }\end{array}$ & $\begin{array}{l}\text { Standard Exceeded in the } \\
\text { Field }\end{array}$ \\
\hline \hline Tree damage (\% of trees that are damaged) & $49 \%$ & $10 \%$ & Yes \\
\hline Root exposure (\% of trees with root exposure) & $1 \%$ & $20 \%$ & No \\
\hline Litter (total number) & 27 pieces & 2 pieces & Yes \\
\hline 'Unplanned' trails (total number) & 2 trails & 6 trails & No \\
\hline
\end{tabular}

Source: [25].

* Mean of observations from 87 developed campsites.

**These standards are the mean responses for all park visitors surveyed, with the lowest unit of analysis being the park rather than a specific site. These standards are based on the expressed preference of $50 \%$ of respondents, relying on the pragmatic view that managers should aim to please at least half of the visitors (see [28, 29] for detailed explanation).

over the last two decades on offshore islands near Perth (Western Australia) [30]. Little information has been published on the impact of tourism and the associated visitors on this species. The State's wildlife management agency has become increasingly concerned about these interactions given that this species has not recovered from a reduction in its range due to sealing in the $19^{\text {th }}$ century and is listed as vulnerable under Australia's Environment Protection and Biodiversity Conservation Act 1999 (Cth).

The focus of the research reported here is Carnac Island, a small uninhabited island protected as a nature reserve (19 ha) and located about $8 \mathrm{~km}$ off the West Australian coast near Perth (the State's capital). Male sea lions haul out on its main beach to sleep and rest. With escalating boat ownership and increasing interest and participation in wildlife tourism, visitor numbers to Carnac Island have grown accordingly. Its easy accessibility, sheltered beach, safe swimming, and safe anchorage, plus bird life and hauled-out sea lions make it an appealing destination [31]. On a busy summer day up to 200 recreational boats may be anchored near the eastern beach where most of the sea lions haul out [30]. Visitor numbers per annum are estimated at 20,000 - 30,000, in the bay adjacent to this beach [31].

Similarly to the forest impacts research, an integrated conceptual model can be used to describe the sea lion research (Fig. 2). In overview, this model describes how behavioral observations of sea lions were combined with survey information on visitors' perceptions of sea lions' behavioral responses to them, to provide an integrated basis for managing sea lion - tourist interactions. This integrated focus was assisted by the interest shown by managers in better understanding the potential impacts of visitors on sea lions so that informed decisions could be made regarding managing the interactions between the two [30].

The study site was the beach on the eastern side of Carnac Island, where up to 45 sea lions haul out at any one time. The study involved 112 hours of field observations of the responses of sea lions to visitors over 2.5 months. This ecological component sought information on whether the rate of return of sea lions to the beach was affected by the level of human visitation, the behavioral responses of sea lions to visitors on the beach, and the spatial distribution of hauled out sea lions on the beach. Only the second aim is addressed here to illustrate the interdisciplinary features of this project. Details on the complete study can be found elsewhere [30].

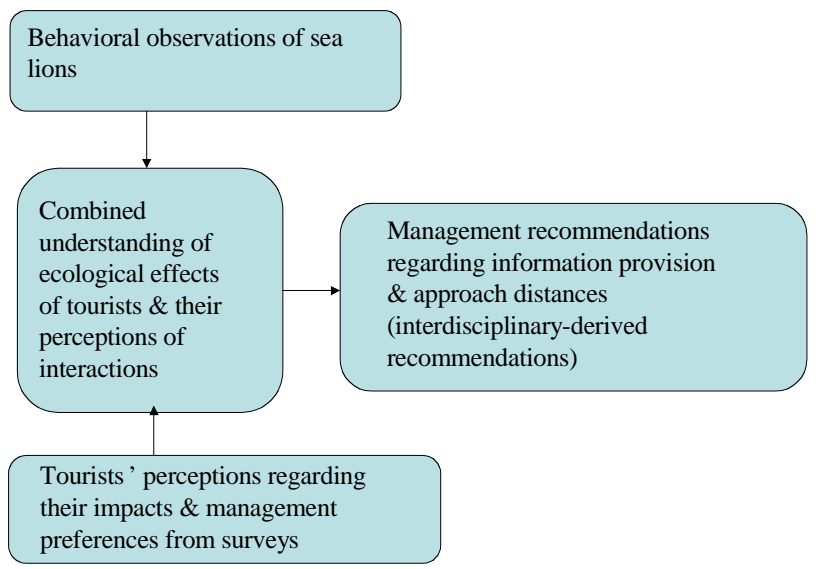

Fig. (2). Conceptual framework for visitor-sea lion interaction research.

Focal animal sampling was used to describe and record the responses of sea lions to humans [30]. Recording of behavior was triggered by humans being within $15 \mathrm{~m}$ of an animal and continued for 1 hour unless the animal under observation moved off the beach or the humans moved away, beyond $15 \mathrm{~m}$. This sampling approach was chosen because sea lions spend most of their time sleeping and resting when humans are not there. As such, random sampling would have resulted in very little behavioral data [30]. Four response categories were used: 'no response' (sea lion showed no visible response when humans were within $15 \mathrm{~m}$ ); 'look' (looking without lifting head); 'lift head' (head lifted); and 'sit up' (animal sat upright facing nearby humans). The variables recorded included time of day, age class of the sea lions (juveniles, immatures and adults), approach distance, and number of humans approaching the sea lion [30].

Similarly to the forest impacts study described above, the social component of this project was also questionnairebased [31]. The questions also reflected management issues of concern to the state wildlife management agency (Department of Environment and Conservation), identified through discussions with their staff. They were concerned about increasing visitor numbers and their potential effect on sea lions as well as visitor safety, given the often-close proximity of visitors to these animals.

A total of 207 visitors completed the questionnaire. They were asked questions about themselves and their activities on 
Table 3. Response Profiles for Sea Lions in the Presence and Absence of Visitors

\begin{tabular}{|l|l|l|l|l|}
\hline Sea Lion Behaviour & No Response (\%) & Look (\%) & Lift Head (\%) & Sit Up (\%) \\
\hline \hline Visitors present & 21 & 45 & 25 & 8 \\
\hline Visitors absent & - & 20 & 32 & 48 \\
\hline
\end{tabular}

Source: [30].

the Island, their interactions with sea lions, and then a number of questions about perceptions: their perceptions of sea lion disturbance by visitors, quality of their experience as a visitor, and safety issues. Questions were also asked about their support for guidelines and regulations on human - sea lion interactions and how sea lion viewing could be improved in the future. The perceptual results are reported here as they are most relevant to the aims of this paper. Other results and the associated discussion are presented elsewhere [31].

Visitors clearly affected the behavior of sea lions. The frequency distribution of the response profile in the presence and absence of humans was significantly different (at $\mathrm{p}<0.001$ ) (Table 3). 'No response' was omitted from this analysis because it did not apply to the behavior profile in the absence of humans [30]. When humans were present, the most common response was looking (45\% of responses). In their absence, it was sitting up (48\% of responses). However, and this is a critical point, responses in the presence of humans are often repeated and therefore prolonged, while in the absence of humans, responses including sitting up are usually brief and associated with social interactions between animals [30].

A range of behaviors was noted [31] (Table 3). This variability was not obvious to visitors, with $98 \%$ noting that the most common sea lion activity was sleeping/resting (Table 4). A similar disjuncture is evident between the ecological results regarding behavioral changes due to the presence of visitors and visitors' perceptions regarding their impact, as reflected in the visitor survey. Sea lion vigilance behavior changed markedly when visitors were present; however, $76 \%$ of those surveyed noted that they did not disrupt sea lions (Table 4) [31]. Repetitive, low-level disturbances of wildlife by humans are often difficult to recognize, even by experienced scientists [32]. A final disjuncture is evident regarding approach distances (Table 4). Sea lions remained vigilant across all approach distances, from less than $2.5 \mathrm{~m}$ to greater than $15 \mathrm{~m}$ [30]. In contrast, $71 \%$ of visitors considered that $5 \mathrm{~m}$ or less was a safe approach distance [31]. The recommended approach distance, by the wildlife management agency, is no closer than 5-10 m.
This ecological and social information, when combined as in Fig. (2) and Table 4, provides invaluable information for managing this species and the associated visitors. Making management recommendations, creating new integrated knowledge as per the requirements of interdisciplinary research [5], is a clear outcome. Recommendations include developing an interpretation program to enable visitors to gain more from their visit, rather than them feeling they have done little more than watching animals sleeping! Also, such a program needs to explain why a minimum approach distance matters (and this distance may be $10 \mathrm{~m}$ or beyond) [31].

\section{DISCUSSION}

A critical analysis of these projects, as interdisciplinary research, can provide insights enabling the potential improvement of current efforts by conservation biologists and those researching ecotourism, as well as others attempting similar research. It is highly likely that a number of the lessons learned and challenges for the future, as discussed below, are discipline independent. To provide these insights we first return to the issues in the context of these projects that have proved problematic for interdisciplinary research: poorly defined terms, lack of common goals, unclear or missing conceptual framework, insufficiently explained methods, and a lack of new knowledge achieved through integration. We then identify and discuss, again based on the two projects reported here, several unresolved challenges for the future.

\section{Interdisciplinary Research - Returning to the Issues}

A major issue identified by a number of researchers $[5,7$, 13] was the need for a common understanding of what the research entailed and the associated terms - was it multidisciplinary, interdisciplinary or something else? In both these projects, it was clearly understood by those involved that interdisciplinary research was needed to answer the questions being raised by managers. For example, for the camping impacts in the south-west forests, managers were interested in knowing if the current levels of impacts were socially unacceptable (to visitors and managers). This required ecological research to measure the field conditions and social research to determine the conditions of importance (for eco-

Table 4. Discrepancies Between the Observed Sea Lion Behavior and Visitor Perceptions of these Behaviors

\begin{tabular}{|l|l|}
\hline Field Observations of Sea Lions & Visitor Survey \\
\hline \hline $\begin{array}{l}\text { Most common sea lion response in the presence of visitors was repeated } \\
\text { 'looking' (45\% of sea lion responses). }\end{array}$ & $\begin{array}{l}\text { Most common sea lion activity when visitors were present was } \\
\text { sleeping/resting (98\% of visitor responses). }\end{array}$ \\
\hline $\begin{array}{l}\text { Visitors absent: behavior very different with 'sitting up' most common (48\%), } \\
\text { but a brief event. Visitors significantly altered animal's vigilance behavior. }\end{array}$ & $76 \%$ of visitors thought they didn't disrupt sea lions. \\
\hline Sea lions remained alert beyond 5-10m recommended approach distance. & $71 \%$ of visitors considered 5m or less a safe approach distance. \\
\hline
\end{tabular}

Sources: $[30,31]$. 
logical measurement) and the levels at which impacts on these conditions became unacceptable.

The applied nature of both projects - providing information for managers - resulted in an implicit sharing of goals, the goal being solving real world ecotourism problems for managers. Successful cross-disciplinary efforts are often underpinned by similar axiological commitments [33]. Axiology refers to the goals underlying a particular approach to science, here with regards to terminal goals (i.e., information provision for managers).

The conceptual frameworks (Figs. 1 and 2) and accompanying methodological details help allay previously raised concerns about interdisciplinary research [5]. The conceptual frameworks, each project-specific, describe how the social and ecological research methods relate to, influence and support each other. For example, Fig. (2) shows conceptually for the sealion - tourist interaction study how behavioral observations of the animals are combined with surveys of tourists to develop management recommendations.

For both projects, the methodological details are both discipline-specific as well as detailing how the social and ecological components inform each other. This interweaving is most evident from the methodological descriptions for the forest study, as described above, where social science (through visitor surveys) determined the conditions of interest, ecological research was used to assess these conditions (e.g. tree damage), and social science (visitor surveys) was again used to develop standards for the acceptable level of impacts on these conditions.

The last issue is the requirement for interdisciplinary studies to produce new knowledge achievable only through taking such an integrated approach. Both projects provided new knowledge potentially useful for managers. The camping impacts project gave information about sites where current conditions exceeded the visitor-determined standards. The sea lion - visitors interaction project revealed the disjunction between how animals respond to visitors and how visitors perceive these responses.

\section{What Made Interdisciplinary Research Possible?}

Being a fox - able to devise many strategies for research - rather than a hedgehog [34] - using a single effective strategy through one's career - potentially contributes to an interest in and ability to undertake interdisciplinary research [8]. Academics to be successful, however, 'must all be certified hedgehogs before they can be foxes' ([8], 324). Most, in the United States and elsewhere, obtain their reputation and professional standing through relatively narrow specializations. And even those who would like to be foxes probably need to remain grounded in their home discipline [8].

Perhaps, however, openness to other disciplines is just as important if not more so than whether a researcher is a fox or hedgehog [8]. Such openness underpins the idea of "critical pluralism', as a means of progressing the inclusion of social science in natural resource management [33]. Critical pluralism is an approach to research where all involved have a tolerant, open attitude to new theories and methods while at the same time being critical (i.e., thinking very carefully) about all methods, theories and results [35]. In the research projects reviewed in this paper, the researchers were foxes, using strategies from several disciplines as well as evidencing an openness or pluralism regarding other disciplines.

Given the above comments, conservation biology, as a science, seems well placed to be open to the inclusion of other disciplines. It has been suggested that the sciences, such as conservation biology, are more open to the social sciences than vice versa [8]. Additionally, the integrative basis of conservation biology [36], and the urgent need to embrace the social as well as natural sciences to address real world problems [4], further contribute to the possibilities for openness. Another way to consider the issue is to regard conservation biology as a single discipline including aspects of the natural and social sciences. The argument then becomes one of the need for the coexistence of a number of different scientific paradigms within this one discipline [33].

Another feature of these two ecotourism research projects that contributed to interdisciplinary success was the researchers adopting the methodological and epistemological systems of ecology rather than those of the social sciences. In the related area of natural resource management, commentators have noted that using an 'ecologically informed' approach provides overarching methods and theory as a basis for investigation [9]. And similarly in wildlife tourism research, such an approach has made interdisciplinary research possible [21]. Conservation biology provides an 'existing methodological, operational, and philosophical framework to address the biological aspects of...multifaceted problems' [9].

In the reviewed projects, empirical, field-based measurements subjected to statistical analysis, characterizing much (but not all) of ecology were used. The epistemological position taken was one of science as describing and recording, rather than interpretation of the findings with or by those being researched. This dualist position, where the researcher is detached from the phenomenon being observed [33], currently dominates ecology and to a large extent conservation biology. Conflicts between epistemologies and methodologies that impede interdisciplinary efforts [37] were avoided here through implicitly adopting this ecologically informed approach [9].

The last reason why interdisciplinary research was possible relates to rewards. A great deal has been written about the rewards that motivate scientists, including funding, publishing in peer reviewed journals, affecting conservation outcomes, improving quality of life for others, creating new knowledge, and maximizing prestige [8, 38, 39]. For these projects, the rewards were successfully completing postgraduate research degrees, publishing in peer-reviewed journals, creating new knowledge, and providing useful information for managers. Additionally, both projects were conducted within a multidisciplinary school so there was peer support for and acknowledgment of the validity of these interdisciplinary approaches.

\section{CONCLUSION: FUTURE CHALLENGES}

Three major challenges remain for conservation biology, ecotourism and other related research areas, such as natural resource management and landscape ecology, as each seeks to actively embrace integrative research approaches. The first is potentially conflicting epistemologies and methodologies $[5,9,10,33,37]$. These conflicts were avoided in the 
reported research through using an epistemological position and methodologies widely accepted in ecology to guide both the ecological and social components of the research. In other projects, such an approach may not be possible or even desirable. In these cases, critical pluralism [33, 35] offers great promise. Such an approach means having a tolerant open attitude to new theories and methods as well as subjecting all knowledge claims (even our own) to critical appraisal.

Conservation biology is well placed to practice critical pluralism. Researchers have repeatedly commented on its broad disciplinary base [36], plus sciences such as this one have been somewhat provocatively suggested as being more open to other perspectives than the social sciences [8]. It will not, however, be easy. As noted with respect to interdisciplinary environmental science efforts 'We will have to overcome...scarce funding, disciplinary institutional traditions and organizational structures, inadequate interdisciplinary training, and insufficient rewards for integrative research. We will have to communicate across divides of vocabulary, reconcile different investigative approaches, and fuse competing paradigms' ([10], 714).

The issue of rewards is particularly vexing and is the second major challenge identified through this research. Several fronts require attention - ensuring adequate funding is available for interdisciplinary research, and providing promotion and publication opportunities for associated researchers. At all these fronts there is cause for optimism by conservation biologists and ecotourism researchers. For both groups funding is available and often encouraged for applied research requiring interdisciplinary approaches, as are promotional opportunities within these research areas. Publication opportunities also exist, however, reviewers are often unable to cope with methods and results spanning rather than sitting within distinct disciplines [13].

The third challenge is how to move forward. Conservation biology has made significant progress in embracing the social sciences with a supportive editorial in 2003 [4] accompanied by the formation of a social sciences working group within the Society of Conservation Biology in the same year. Addressing the two challenges raised above will be essential for further progress to occur. Encouraging strongly applied research will push conservation biologists, and researchers in other related research areas such as ecotourism, to increasingly adopt interdisciplinary approaches. An emphasis in the teaching of conservation biology, beyond building an appreciation of the social sciences [4], on building knowledge of the philosophy of science and the assumptions that accompany all scientific research traditions (e.g., epistemological, ontological, axiological) is imperative. This is not going to be easy either.

Whether we like it or not the transformations in research practice and the associated researchers to undertake interdisciplinary research are essential if the complexity of today's problems in conservation biology and the environment more generally are to be addressed. Conservation biologists and others seeking to solve environmental problems must be willing to explore new and apparently incongruous ideas through interdisciplinarity [37]. Such research offers the potential to find out much more than we ever expected about complex adaptive systems and the nature of real-world environmental systems [10]. Lastly, sustainability is an integra- tive term, so if we are to seek it we must embrace the associated need for interdisciplinary research if conservation biology is to contribute to the broader societal push towards this goal.

\section{ACKNOWLEDGEMENTS}

This research was supported by the Commonwealth Government of Australia through the Sustainable Tourism Cooperative Research Centre. The comments of two anonymous reviewers improved the quality of this paper.

\section{REFERENCES}

[1] Vig NJ, Kraft ME, Eds. Environmental policy: new directions for the twenty-first century. Washington (DC): CQ Press 2006.

[2] Dovers S, Wild River S, Eds. Managing Australia's environment. Leichhardt (NSW): The Federation Press 2003.

[3] Ravetz JR. What is post-normal science? Futures 1999; 31: 647-53.

[4] Mascia MB, Brosius JP, Dobson TA, et al. Conservation and the social sciences. Conserv Biol 2003; 17: 649-50.

[5] Tress G, Tress B, Fry G. Clarifying integrative research concepts in landscape ecology. Land Ecol 2004; 20: 479-93.

[6] Warren WA. Hierarchy theory in sociology, ecology, and resource management: a conceptual model for natural resource or environmental sociology and socioecological systems. Soc Nat Resour 2005; 18: 447-66.

[7] Choi BCK, Pak AWP. Multidisciplinarity, interdisciplinarity and transdisciplinarity in health research, services, education and policy: 1. definitions, objectives, and evidence of effectiveness. Clin Invest Med 2006; 29: 351-64.

[8] Strober MH. Habits of the mind: challenges for multidisciplinary engagement. Soc Epist 2006; 20: 315-31.

[9] Rosa EA. The quest to understand society and nature: looking back, but mostly forward. Soc Nat Resour 1999; 12: 371-6.

[10] Kinzig AP. Bridging disciplinary divides to address environmental challenges. Ecosystems 2001; 4: 709-15.

[11] Tress B, Tress G, Décamps H, d'Hauteserre AM. Bridging human and natural sciences in landscape research. Land Urb Plan 2001; 57: 137-41.

[12] Becker E. In: Anon, Ed. Knowledge for sustainable development. An insight into the encyclopedia of life support systems. Volume III. Oxford (UK): UNESCO Publishing-Eolss Publishers 2002; pp. 949-63.

[13] Höchtl F, Lehringer S, Konold W. Pure theory or useful tool? Experiences with transdisciplinarity in the Piedmont Alps. Environ Sci Pol 2006; 9: 322-9.

[14] Tress B, Tress G. Capitalising on multiplicity: a transdisciplinary systems approach to landscape research. Land Urb Plan 2001; 57: 143-57.

[15] Tress G, Tress B, Fry G. Integrative studies on rural landscapes: policy expectations and research practice. Land Urb Plan 2005; 70: 177-91.

[16] Newsome D, Moore SA, Dowling RK. Natural area tourism: ecology, impacts and management. Clevedon (UK): Channel View Publications 2003

[17] Robertson DP, Hull RB. Beyond biology: toward a more public ecology for conservation. Conserv Biol 2001; 15: 970-9.

[18] Drew JA, Henne AP. Conservation biology and traditional ecological knowledge: integrating academic disciplines for better conservation practice. Ecol Soc 2006; 11: 34 .

[19] Fennell DA. Ecotourism: an introduction. London, (UK): Routledge 2003.

[20] Meffe GK. Conservation biology: into the millennium. Conserv Biol 1998; 12: 1-3.

[21] Rodger KJ. Wildlife tourism and the natural sciences: bringing them together. $\mathrm{PhD}$ [dissertation]. Perth (WA): Murdoch University 2007.

[22] Myers N, Mittermeier RA, da Fonesca GAB, Kent J. Biodiversity hotspots for conservation priorities. Nature 2000; 403: 853-8.

[23] Shepherd DP, Beeston GR, Hopkins AJM. Native vegetation in Western Australia: extent, type and status. Perth (WA): Department of Agriculture 2002.

[24] Carlsen J, Wood D. Assessment of the economic value of recreation and tourism in Western Australia's national parks, marine 
parks and forests (draft). Queensland (Australia): Cooperative Research Centre for Sustainable Tourism 2004.

[25] Smith AJ. Campsite impact monitoring in the temperate eucalypt forests of Western Australia: an integrated approach. Ph.D.[dissertation]. Perth (WA): Murdoch University 2003.

[26] Smith AJ, Newsome D. An integrated approach to assessing, managing and monitoring campsite impacts in Warren National Park, Western Australia. J Sustain Tour 2002; 10: 343-59.

[27] Cole DN. Monitoring the condition of wilderness campsite. Ogden (Utah): USDA Forest Service Intermountain Forest and Range Experiment Station. 1983; Research Paper INT-302.

[28] Roggenbuck JW, Williams DR, Watson AE. Defining acceptable conditions in wilderness. Environ Manage 1993; 17: 187-97.

[29] Morin SL, Moore SA, Schmidt W. Defining indicators and standards for recreation impacts in Nuyts Wilderness, WalpoleNornalup National Park, Western Australia. CALM Science 1997; 2: 247-66

[30] Orsini J-P, Shaughnessy PD, Newsome D. Impacts of human visitors on Australian Sea Lions (Neophoca cinerea) at Carnac Island, Western Australia: implications for tourism management. Tourism Mar Environ 2006; 3: 101-15.

[31] Orsini J-P, Newsome D. Human perceptions of hauled out Australian Sea Lions (Neophoca cinerea) and implications for manage- ment: a case study from Carnac Island, Western Australia. Tourism Mar Environ 2005; 2: 129-32.

[32] Duffus DA, Dearden P. Non-consumptive wildlife-orientated recreation: a conceptual framework. Biol Conserv 1990; 53: 213-31.

[33] Patterson ME, Williams DR. Paradigms and problems: the practice of social science in natural resource management. Soc Nat Resour 1998; $11: 279-95$

[34] Gould SJ. The hedgehog, the fox, and the magister's pox: mending the gap between science and the humanities. New York (US): Harmony Books 2003.

[35] Hunt SD. Positivism and paradigm dominance in consumer research: towards critical pluralism and rapprochement. J Consume Res 1991; 18: 32-44.

[36] Hunter ML. Fundamentals of conservation biology. Cambridge (MA): Blackwell Science 1996.

[37] Weissinger E. Of revolutions and resistance: a response to philosophical criticisms of social scientific leisure research. J Leis Res 1990; 22: 309-16.

[38] Mulkay M. Sociology of science: a sociological pilgrimage. Milton Keynes (UK): Open University Press 1991.

[39] Ziman J. Real science: what it is and what it means. Cambridge (UK): Cambridge University Press 2000.

(C) Moore et al.; Licensee Bentham Open.

This is an open access article licensed under the terms of the Creative Commons Attribution Non-Commercial License (http://creativecommons.org/licenses/by-nc/3.0/) which permits unrestricted, non-commercial use, distribution and reproduction in any medium, provided the work is properly cited. 